\title{
Development of Simulink Model to Investigate Control Structure, Safety, and Stability of a Water Brake System at Main Engine in House 5 Laboratory: Warnemünde
}

\author{
Axel Rafoth ${ }^{1}$, Wolfgang Busse ${ }^{2}$, Muhammad Tri Kurniawan ${ }^{3}$ \\ (Received: 31 July 2017 / Revised: 29 April 2019 / Accepted: 24 June 2019)
}

\begin{abstract}
So that can find a safe point and control safety. After this, the essential system component will be created the model in block diagram and the block diagram will be simulated with Simulink. This requires a model of combustion machine and its control as well as break system and its control. The valve angle also affects the amount of flow or discharge of water which resides in the brake system. The amount of water flow in the brake system affects the amount of load that will be accepted by the main engine. The model is to be validated with measured data. To define load characteristics for a parallel operating visualization, these load characteristics are to be simulated. The results of the modeling were to know PI controller parameters to control the main engine. In the investigation, then simplify the process of modeling results are displayed in the form of a curve. Where in the curve we can see the performance of the engine and brake system so that the operation of the main engine will get maximum condition within safe limits.
\end{abstract}

Keywords — controller, diesel engine, fuel oil consumption, matlab, modeling, simulink, water brake system

\section{INTRODUCTION}

$\mathrm{F}$ or laboratory operation, the University of Applied

Sciences Wismar in Warnemünde is using the main diesel engine. A water brake loads the diesel engine and sets desired work points and work curves. The water vortex brake is to be controlled by PLC. In order to find suitable controller parameters for the control and to define safety settings.

By modeling every essential system component, we can find a suitable controller parameter for the control and define safety settings. The Model is to be validated with measured data. To define load characteristics for a parallel operating visualization, these load characteristics are to be simulated. So that the entire system is to be modeled in a Simulink model or Matlab.

The results of the modeling were to know PI controller parameters to control the fuel of main engine. The output from the PI controller is a weighted sum of the input signal, the integral of the input signal. The weights are the proportional and integral gain parameters. So, PI controller can set the delay time on engine speed. That will have an effect on the stability of the engine. The

Axel Rafoth, Department of Maritime Studies, Faculty of Engineering, Hochschule Wismar, Rostock 18119, Germany, Email : axel.rafoth@hs-wismar.de

Wolfgang Busse, Department of Maritime Studies, Faculty of Engineering, Hochschule Wismar, Rostock 18119, Germany, Email : wolfgang.busse@hs-wismar,de

Muhammad Tri Kurniawan, Department of Marine Engineering, Institut Teknologi Sepuluh Nopember, Surabaya 60111, Indonesia, Email : mtrikurniawan99@gmail.com input of the block is typically an error signal, which is the difference between a reference signal and the system output.

The modeling is divided into two processes, namely the static process and dynamic process. The static process is the process of retrieving data based on test running engines. After the data has been obtained further modeling on Simulink based work system on the engine. The model consists of a mathematical model of the engine and the results of the modeling will be validated according to the results of running engines. A dynamic model of the Simulink dynamometer was constructed to aid development of the controller. It is a tool to experiment with controllers more easily than with the actual hardware. So, in this dynamic process, we can create variations of the rotation of the engine and the torque engine.

In the investigation, then simplify the process of modeling results are displayed in the form of graphs. Where in the graph we can see the performance of the engine and brake system so that the operation of the main engine will get maximum condition within safe limits.

The Hydraulic Power Brake 9N38/12F also referred to as a water brake, is directly coupled to the MAN B\&W $6 \mathrm{~L} 23 / 30 \mathrm{~A}$ [1] main engine via a rigid shaft. It is used to deceleration of engine drive and designed for direct coupling to this engine [2]. The hydraulic power brake is a type of fluid coupling used to absorb mechanical energy and usually mounted in an enclosure filled with water [3]. The hydraulic power brake concept is generally based on centrifugal pumping laws. A centrifugal pump works on the concept of displacing fluid radially from its inlet to its outlet, about the enclosure.

The brake consists of rotating parts, oscillating, and standing parts. It is made up of a rotor composed of the clutch, shaft, and impeller, as well as the stator with the brake arm with the housing and the housing inserts, 
(pISSN: 2541-5972, eISSN: 2548-1479)

which are called pendulum bodies. The rotors and the brake has a pendulum body shaped half shell, water levels are regulated by electro-mechanical valve units (actuators and valve vane) controlled by the LSE.

It achieves its maximum capacity when the blades are completely loaded, that is the housing chambers are filled with operating water [2]. This makes it clear that one of to control the amount of load on the engine is controlled filling level. For the plant in the engine laboratory, only outlet valve can be controlled electromechanically by the PRE and LSE, the inlet valve is to be actuated manually and has no significance for the automatic control. The pressure and the amount of water flow adjusted by the opening of the electro-mechanical outlet valve.

The Program Control Unit (PRE/PCU) and the Power Stage Unit (LSE/PSU) take over the control function of the system. By setting the speed or the torque of the brake, the PRE generates a position signal for the valve, which leads to an adjustment of the valve unit by the control in the LSE. The load on the valve is adjusted by voltage regulation of a phase-angle control [2].

These models estimate the hydrodynamic torque absorption $T_{\text {brake }}$ of such a brake depending on the power of engine $P$ and the engine speed / angular velocity, $\omega$ (figure 1). The input on the model is the engine speed and torque reference. The main output is the actual power and torque on a dynamometer. In order to determine that value, then the value of the power obtained by the following equation.

$$
P=\dot{m} \times C v \times \eta
$$

Where the value of flue rate, $\dot{m}$, derived from the value of PI controller are adjusted with the result of running engines. Calorific value, $\mathrm{Cv}$, obtained from the project guide specifications of engine $6 \mathrm{~L} 23 / 30 \mathrm{~A}$ and the efficiency engine, $\eta$, assumed $30 \%-40 \%$.

To find out the actual torque values using the following equation,

$$
T=\frac{P}{\omega}
$$

To find out the angular velocity values, $\omega$ can use the following equation,

$$
\begin{aligned}
& \alpha=\frac{T}{l} \\
& \alpha=\frac{d \omega}{d t} \\
& \omega=\int \alpha d t \\
& \omega=\int \frac{T}{l}
\end{aligned}
$$

Where $\alpha$ are angular acceleration, $\mathrm{rad} / \mathrm{s}^{2}$. The torque, $\mathrm{T}$, is the torque reference value and moment of inertia, $\mathrm{J}$, in $\mathrm{Kgm}^{2}$. Simulink is a graphical extension of MATLAB for modeling and simulation of systems [4]. The main advantages of Simulink are the ability to model a nonlinear system, which a transfer function is unable to do. Another advantage of Simulink is the ability to take on initial conditions. Simulink is integrated with MATLAB and data can be easily transferred between the programs. When a transfer function is built, the initial conditions are adjusted to the given reference value. Systems in Simulink are drawn on block diagrams. As well as virtual input and output devices such as function generators and oscilloscopes.

\section{METHOD}

\section{A. The Control Response of the PI Controller}

The PI Controller first compares the desired value (reference variable) with the detected value of the process. The comparison provides the control difference. The dynamic behavior of the PI controller continuously compensates for this difference, and supplies at the output a control variable, which always follows the setpoint. Thus, the adjustment range of the control variable is the same as the setting range of the setpoint.
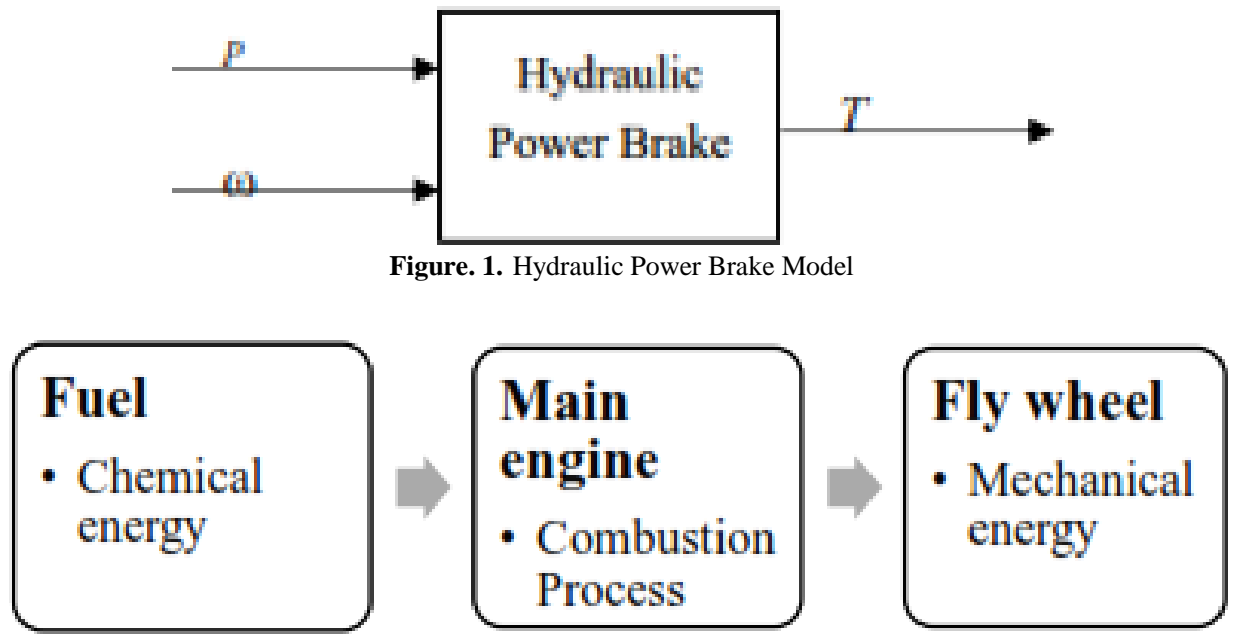

Figure. 2. The Setting Lever of ENITECH 


\section{B. Engine Monitoring and Control System}

The main engine monitoring and parts of the brake control system have been enhanced by the company ENITECH Energietechnik-Elektronik $\mathrm{GmbH}$ in 2012 and remodeled [5]. Consequently, eliminates the adjustment of speed and torque of the brake using the front panel of the PRE 420. The reference potentiometer of PRE is set and inoperative. There was the new adjustment of ENITECH installed. The adjustment of speed and torque of the brake using the front panel of the PRE 420 and using lever control.

\section{Engine Performance}

Proceedings against the performance of engine involve several stages in generating power that is generated [6]. In figure 2 shows there are 3 stages in the generated power generating engine. The first stage is the energy derived from fuel, as shown in the equation 7 as follows;

$$
P_{\text {eng }}=\dot{m} \cdot C_{v}
$$

The energy produced is not fully used to generate power output, the energy losses caused by heat loss in cooling and exhaust, pumping loss and also friction on the component of engine. So that only about $30 \%-40 \%$ of the energy used to produce the power output. So, the equation becomes same with equation 1 ;

$$
P \text { eng }=m \cdot C v \cdot \eta
$$

In the second stage is the combustion process, engine power can be expressed as follows,

$P$ eng $=b m e p \cdot L \cdot A \cdot n$

From equation 8 shows that the magnitude of engine power depends on the amount of brake mean effective pressure (BMEP) occurring in the engine, due to the Length of stroke (L), Area of piston-bore (A), and Rate of power strokes (n) on an engine is fixed. So, in other words, the amount of engine power is proportional to the value of BMEP that occurs.

The third stage is the power engine measured by the braking method in the engine test bed, which is the power output of the engine as shown in the equation 10 as follows;

$$
\begin{aligned}
& P_{\text {eng }}=T . \omega \\
& \omega=\frac{N}{(60.2 . \pi)}
\end{aligned}
$$

Where $\mathrm{T}$ is the torque $(\mathrm{Nm}), \omega$ is the angular velocity $(\mathrm{rad} / \mathrm{s})$ and $\mathrm{N}$ is the engine speed (rpm). Based on the equation 9 it appears that a significant change in engine power can only be done by changing the value of the torque engine. Each potential variable in the equation 1, equation 8 , and the equation 9 has an attachment and influence proportionately, so that the condition may be simplified as follows;

$\dot{m} \infty$ bmep $\infty \quad \mathrm{T}$

It means "engine torque $(\mathrm{T})$ value will be significantly changed if in combustion process inside cylinder there is a change of brake mean effective pressure (bmep) value. And the bmep value change depends on the amount of mass fuel rate $(\dot{m})$ supplied to the engine ".

TABLE 1.

DATA FROM RUNNING ENGINE

\begin{tabular}{cccc}
\hline $\begin{array}{c}\text { Speed } \\
(\mathrm{rpm})\end{array}$ & $\begin{array}{c}\text { Torque } \\
(\mathrm{Nm})\end{array}$ & $\begin{array}{c}\text { Power } \\
(\mathrm{kW})\end{array}$ & $\begin{array}{c}\text { Fuel rate } \\
(\mathrm{kg} / \mathrm{h})\end{array}$ \\
\hline 568 & 4000 & 237.93 & 54.8 \\
713 & 6430 & 480.11 & 104.7 \\
818 & 8400 & 719.57 & 150 \\
900 & 10230 & 964.18 & 203 \\
\hline
\end{tabular}

\section{RESULTS AND DISCUSSION}

\section{A. Simulink Model of the System}

For modeling in Simulink, we must know how the system works. In figure 3, shown the simple model of engine working system. The inputs to the simulation are an engine speed. The speed of engine will produce the flow rate of fuel by PI controller (engine control block).
The amount of flow rate of fuel will produce the power of the engine by multiplying the calorific value of engine and efficiency engine (engine process block). The main output is actual torque at the engine.

Base on figure 3 , the simple diagram developed to be the complex block diagram with be equipped by the time delay in every given input data. So, the transfer block can be grouped into several subsystems. (figure 4): 


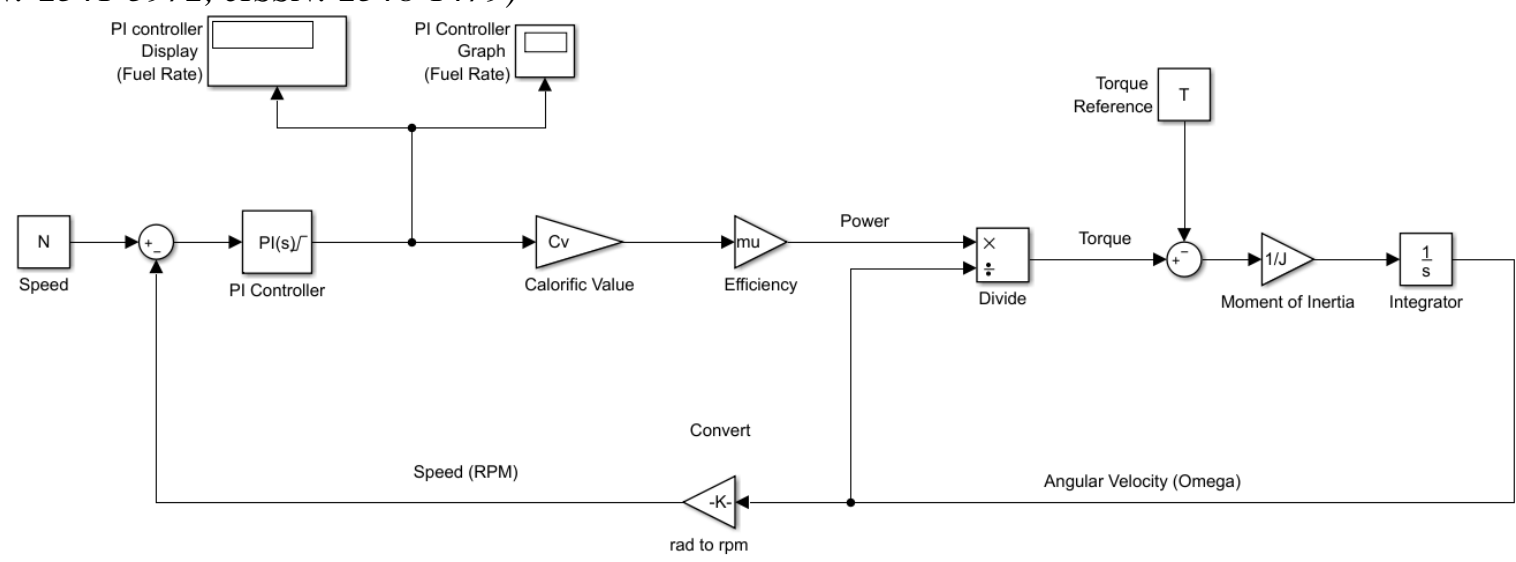

Figure. 3. Simple Model of Engine Working System

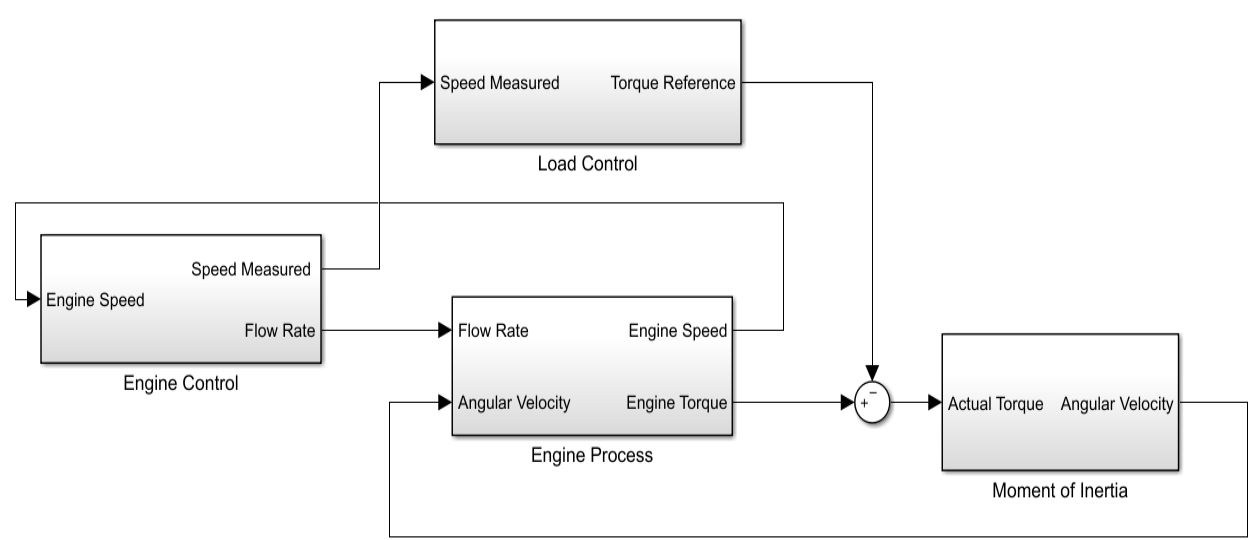

Figure. 4. Overview of the Engine Working System at Simulink Model

\section{PI Controller}

The inputs $(\mathrm{u})$ to the controller are the speed of the engine and input torque at the engine input shaft are presented on figure 5. Its outputs (y) are the amount of the flow rate of the fuel engine and proportional directional valve of dynamometer driving pump displacement commands. The clamping circuit is to stops integration when the sum of the block components exceeds the output limits and the integrator output and block input have the same sign. Resumes integration when the sum of the block components exceeds the output limits and the integrator output and block input have opposite sign [7]. The clamping circuit implements the logic necessary to determine whether integration continues. This controller varies the fuel injection pump to be transferred for the engine to control the power output.

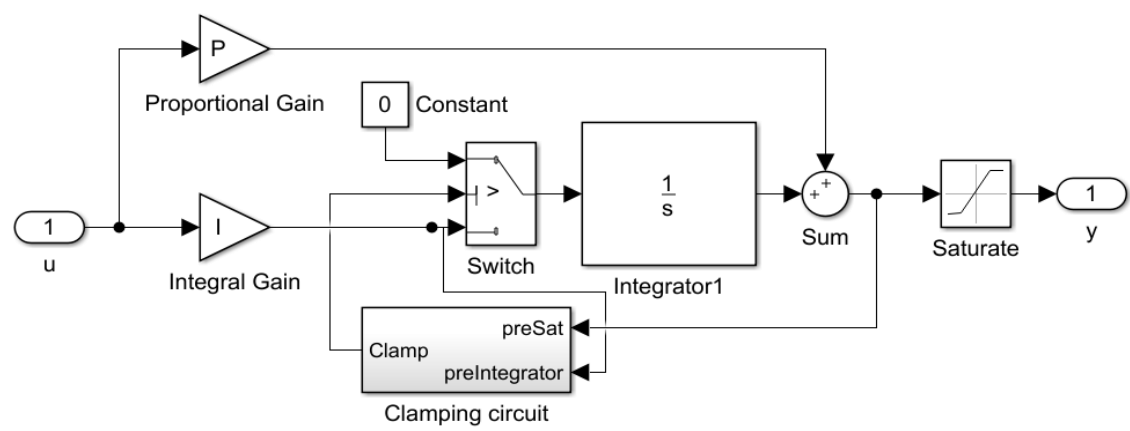

Figure. 5. PI Controller Block Transfer Diagram

\section{Engine Control Block}

Engine control block serves to control the amount of fuel flow to be transferred to the engine. It is shown on figure 6 The input to this subsystem is the speed reference and speed generated by engine or engine speed. Speed reference is the initial speed value assigned to the engine. Then the second input is engine speed. Value at engine speed is obtained from engine process block. Where the value at engine speed will be filtered to the value of oscillation produced engine speed. So, the engine speed will produce speed measured. Then the speed reference will be in subtract with speed measured value to minimize the error value.

The subtract will go to the PI controller block to set the amount of fuel rate to be transferred to the engine process block. The PI controller block is equipped with a saturation function that acts as the injection working limit of the fuel pump. Where the fuel injection limit is obtained from equation 1 using maximum power.

So, the output of engine control bock is speed measured and the flow rate of fuel. 


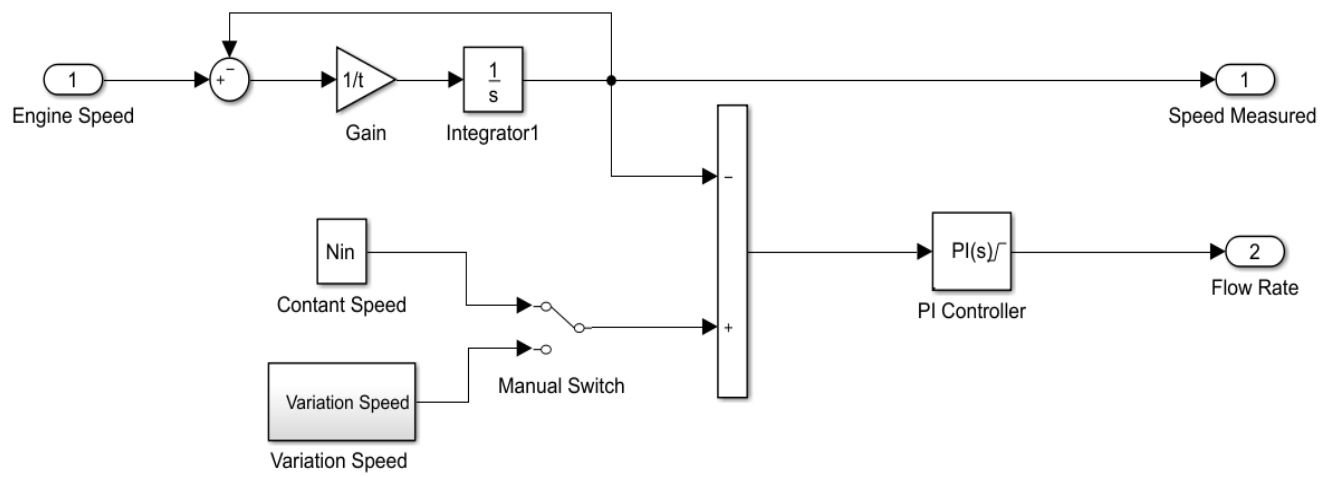

Figure. 6. Transfer Block on the Engine Control Block

\section{Static Process Analysis}

We The static process characteristic is a curve that gives the steady state relation between input signal " $u$ " and output signal " $y$ ". The curve has a physical interpretation only for a stable process. All process investigation should start by a determination of the static process model. It can be used to determine the range of control signal required to change the process output over the desired range, to size actuators, and to select sensor resolution. It can also be used to assess whether static gain variations are so large that they have be accounted for in the control design.

The static model can be obtained by an open-loop experiment where the input signal is set to a constant value and the process output is measured when it has reached steady state. This gives one point on the process characteristics. The values of the speed, torque, and power are required basic components and for the manual start of an operating point of the prime mover. All other displays are optional for direct operation. The lever position is shown on the monitor of the motor control. The data obtained from "Enitech Logtool" monitor display while running engine.

To set the parameters of the corresponding PI controller on the engine. Making this model will be tailored to the results of the test engine running. In the original design of the system, the torque or speed through two reference potentiometers are set. In the deviation of the specified value of the applied speed or torque value, this means adjusting the combustion and power rate to achieve the required process parameters (figure 9). By setting a torque and a speed reference potentiometer generates the corresponding set point for speed $(\mathrm{N})$ and torque $\left(\mathrm{T}_{\text {load }}\right)$. From calculation on the system, the controller receives information about the size of the currently applied actual value from speed (N') and torque $(\mathrm{T})$. Actual value $\left(\mathrm{N}^{\prime}\right)$ and setpoint $(\mathrm{N})$ of speed are compared in an operational amplifier which is configured as a subtractor with each other. The result of this comparison is the difference between the potentiometer set at the desired value for the rotational speed $(\mathrm{N})$ with the measured actual value for at the brake speed ( $\left.\mathrm{N}^{\prime}\right)$. This value is corrected in PI controller and then the desired value for the fuel rate $(\dot{m})$.

The target value fuel rate $(\dot{m})$ of the PI controller is validated by the measured data on the "Enitech Logtool" monitor display while running engine. The value of the fuel rate $(\dot{m})$ generated by the PI controller is multiplied by the transfer function (TF1) to obtained the power value $(\mathrm{P})$ of the engine (equation 1$)$.

Calorific value $(\mathrm{Cv})$ obtained from project guide specification engine 6L23/30A and efficiency of the engine $(\eta)$ assumed $30 \%-40 \%$. The power value $(P)$ divided with the angular velocity $(\omega)$ to get the actual torque value ( $\mathrm{T}$ ) (equation 2 ).

Actual value $(\mathrm{T})$ and setpoint $\left(\mathrm{T}_{\text {load }}\right)$ of torque are compared in an operational amplifier which is configured as a subtractor with each other. The result of this comparison is the difference between the potentiometer set at the desired value for the actual torque $(\mathrm{T})$ with the value for the torque of load $\left(\mathrm{T}_{\text {load }}\right)$. This value will use to get the angular velocity $(\omega)$ (equation 6).

Where $\alpha$ is the angular velocity in $\mathrm{rad} / \mathrm{s}^{2}$. The torque (T) used are the torque reference and the moment of inertia (J) $\mathrm{Kgm}^{2}$.

One we know the engine working system described in chapter 5 and using the simple model in chapter 6 of figure 7 , the following simulation result are presented on table 2 .

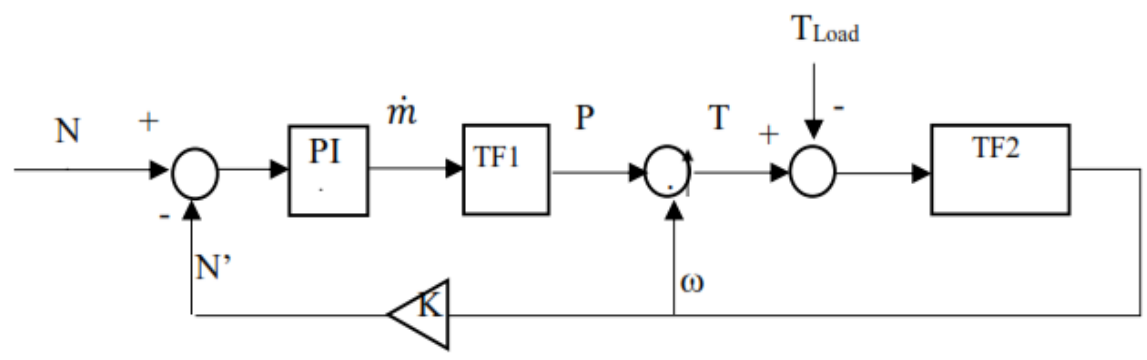

Figure. 7. Schematic Diagram of the System 
TABLE 2.

\begin{tabular}{ccc}
\multicolumn{3}{c}{ MEASURED DATA AND STATIC MODEL RESULT } \\
\hline $\begin{array}{c}\text { Speed } \\
(\mathrm{rpm})\end{array}$ & \multicolumn{3}{c}{$\begin{array}{c}\text { Fuel rate } \\
(\mathrm{Kg} / \mathrm{h})\end{array}$} \\
\cline { 2 - 3 } & Measured Data & Static Model \\
\hline 568 & 54.8 & 54.93 \\
713 & 104.7 & 104.8 \\
818 & 150 & 151.6 \\
900 & 203 & 203.1 \\
\hline
\end{tabular}

a. Analysis of Factor Losses

The losses factor is the loss of power in the engine. As for some factors that affects the factor losses are as follows:

- Heat escaping from the cylinders and the engine.

- Friction between moving parts converts some of the energy to heat which is dissipated to the environment.

- Pumping fuel to the engine.

- Incomplete combustion.

- Braking.

The model on figure 8 aims to find out how much value losses that occur in power and torque engine.
Where power losses engine varied. Furthermore, the power of chemical process in subtract with power losses then multiplied by efficiency engine to produce mechanical power in engine. To calculate the losses in torque, angular velocity factor obtained by using the equation.

$$
\text { Factor } \omega=\left(\frac{\omega}{\text { orated }}\right)^{\wedge} 4
$$

Then, the torque losses multiply the factor of angular velocity.

By simulating the model, so we can know the amount of fuel rate generated from PI controller then validated with measured data that are presented on table 3.

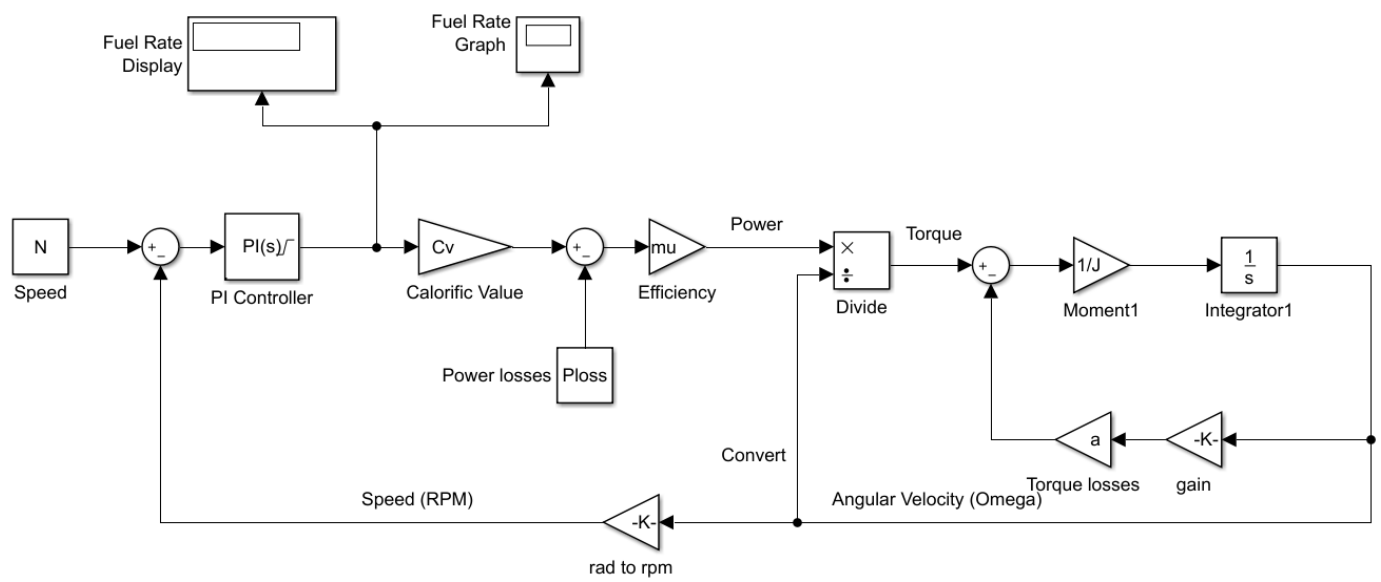

Figure 8. Extension of Simulink Model to Find Factor Losses

TABLE 3.

MEASURED DATA AND MODEL WITH LOSES FACTOR

\begin{tabular}{ccccc}
\hline \multirow{2}{*}{$\begin{array}{c}\text { Speed } \\
(\mathrm{rpm})\end{array}$} & \multicolumn{2}{c}{$\begin{array}{c}\text { Fuel rate } \\
(\mathrm{Kg} / \mathrm{h})\end{array}$} & $\begin{array}{c}\text { Power Losses } \\
(\%)\end{array}$ & $\begin{array}{c}\text { Torque } \\
\text { Losses }(\%)\end{array}$ \\
& Measured Data & Model & & \\
\cline { 2 - 4 } & 54.8 & 54.81 & 5.5 & 4 \\
713 & 104.7 & 104.9 & 2 & 2.1 \\
818 & 150 & 149.7 & 5 & 3 \\
900 & 203 & 202.8 & 5 & 1 \\
\hline
\end{tabular}


The block transfer in this block describes the process of generating mechanical energy in the engine through a chemical energy process.

Fuel rate generated from PI controller multiplied by calorific value and efficiency engine will generate power engine. Then the power engine divided by angular velocity will produce engine torque. The value of angular velocity comes from the moment of inertia.
So, the output of engine process block is the engine torque and engine speed. The block transfer on the engine process block is shown on figure 9 .

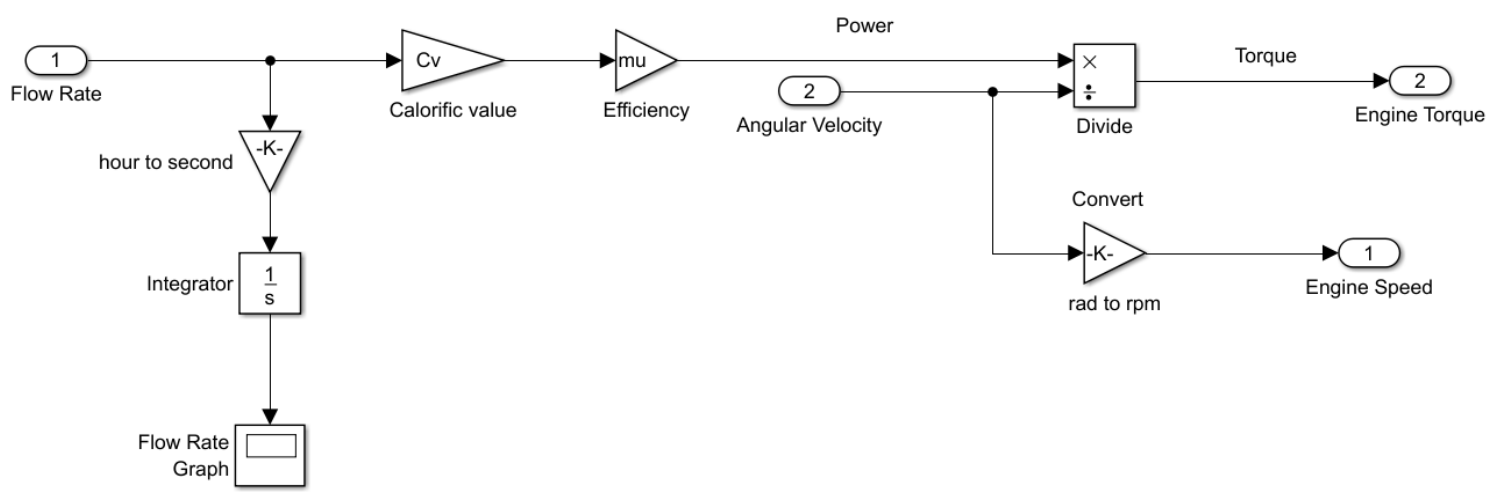

Figure. 9. Transfer Block on the Engine Process Block

\section{Load Control Block}

Load control block serves to control the torque reference to the engine is presented on figure 10 . The input to this subsystem is the speed measured and step of input torque parameter.

\section{Inertia Block}

Then the engine torque will be in subtract with torque reference value to minimize the error value and get the actual torque. Actual torque is what will be the input on the moment of inertia block. Where the output on this block is the speed of engine speed.

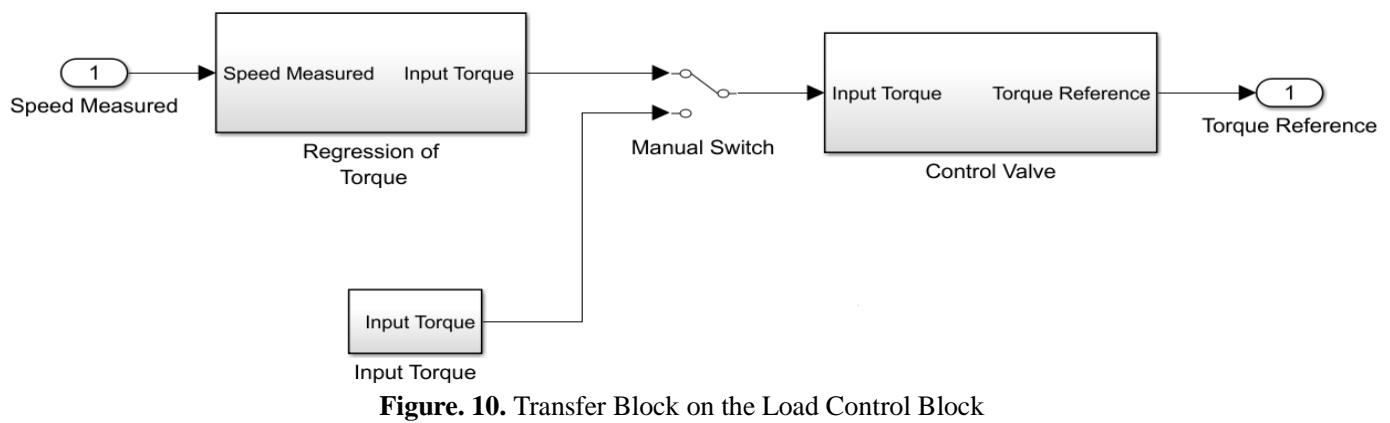

\section{B. Model Validation}

Model validation is performed to ensure that the model in Simulink is working correctly or not. So, the model in Simulink will display the same result or close to measured data. There are three process of model model validation, they are Convert data process, Static process and Dynamic process.

\section{Convert Data Process}

The data must be convert from analog signal to digital signal. The data obtained from in-touch software.

Figure 11 and figure 12 are presented the result of measured and reference data of speed variation on rpm and velocity.

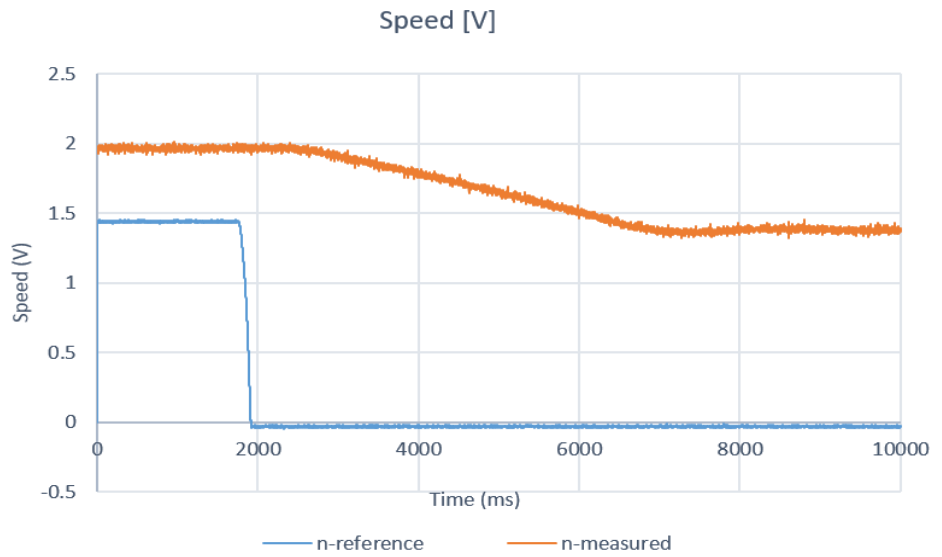

Figure. 11. Graphic of Variation Speed (V) 


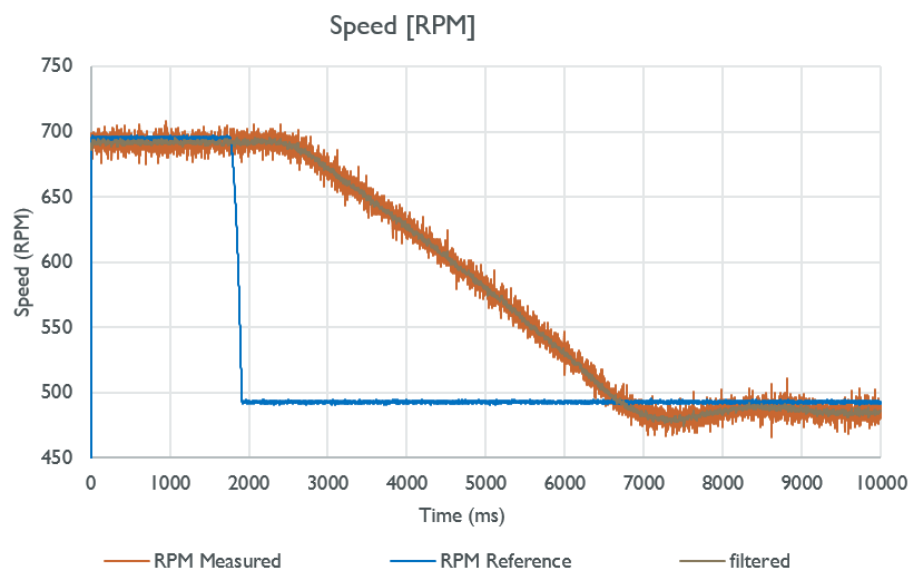

Figure. 12. Graphic of Variation Speed (RPM)

\section{2. $\quad$ Static Process}

On static process, the data of engine simulation is validated by compare the measured data with data from model simulation with and without loss factor.
Figure 13 presents the diagram of static process validation on engine speed variation (rpm).

\section{Static Process Validation}

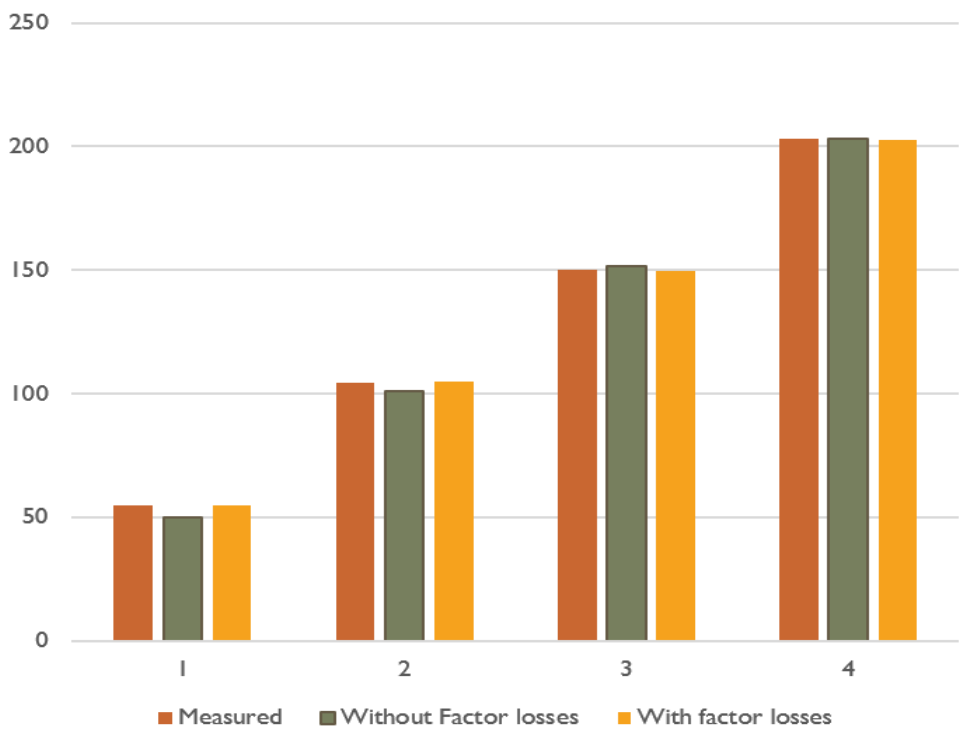

Figure. 13. Graphics Comparison Data of the Fuel Rate

\section{Dynamic Process}

a. Variation Speed

Where perform a speed variation with fixed load at $2000 \mathrm{Nm}$. So, it can be seen the value of the initial speed of the engine $692 \mathrm{rpm}$ then at 2.3 seconds, the speed is reduced to $485 \mathrm{rpm}$. At the time of the decrease, there is a time required to reach the value $485 \mathrm{rpm}$, it can be seen in the figure 14 (a) by "RPM Measured". Figure 14 (b) present the graphic of the system at Simulink Model.

\section{b. Variation Load}

In this case by varying the load of the engine and so get a graph of the system as in figure 15. Base on dynamic model with variation load and data from excel. The minimum torque of the chirp signal was 1071.43 $\mathrm{Nm}$ and the maximum was $5000 \mathrm{Nm}$. The speed of the engine remains on the specified $852 \mathrm{rpm}$ conditions. At the time of the decrease in the load, there is a significant speed surges (image graphics system).

Here the function PI controller is needed to restore the speed surges back to the initial speed condition by adjusting the amount of fuel that goes into the engine. 


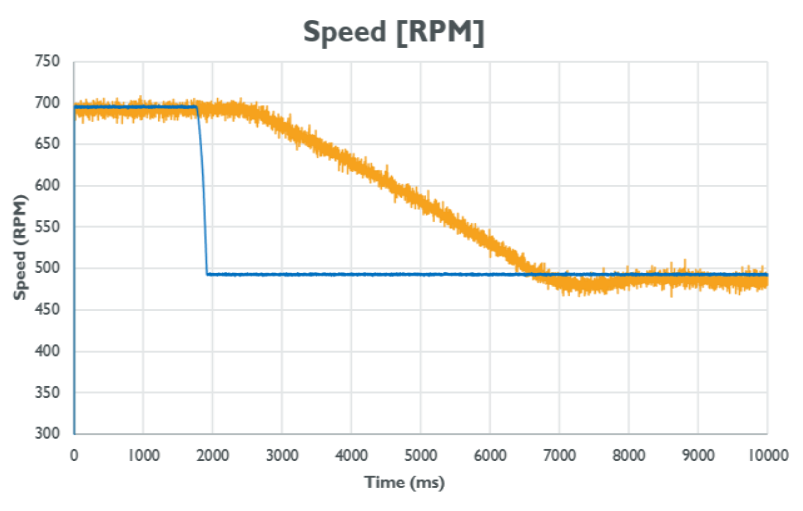

(a)

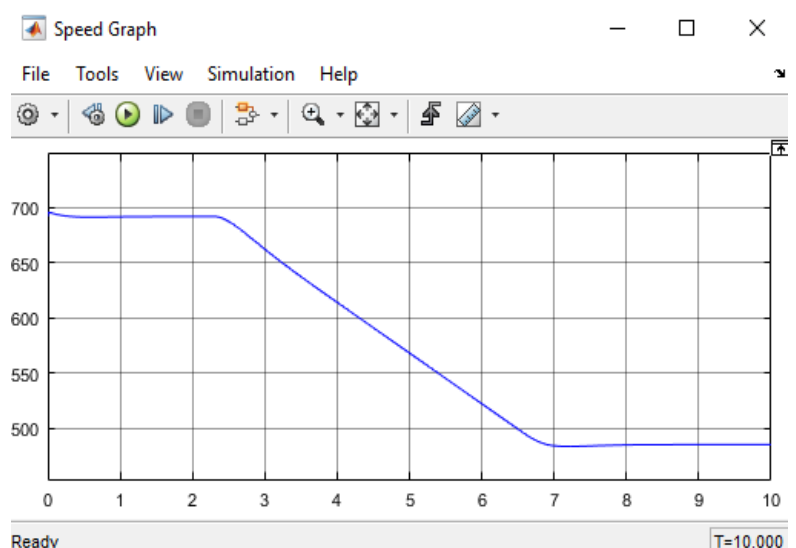

(b)

Figure. 14. (a) Graphic of the System with Variation Speed (b) Graphic of the System with Variation Speed at Simulink Model

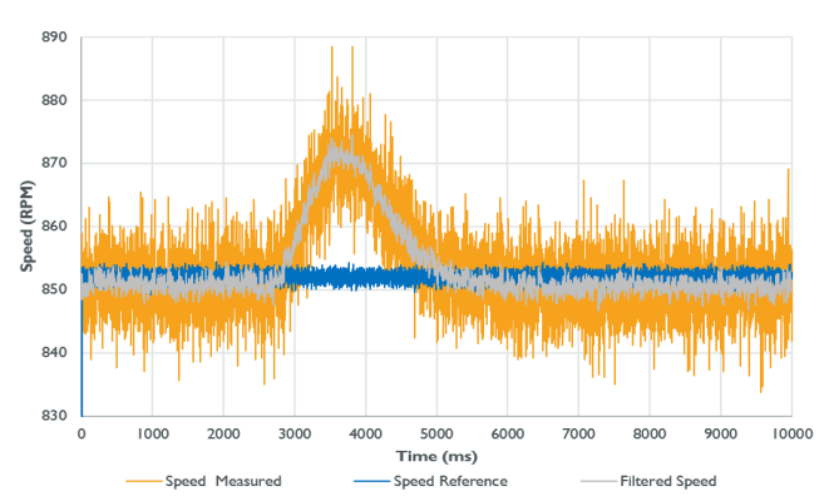

(a)

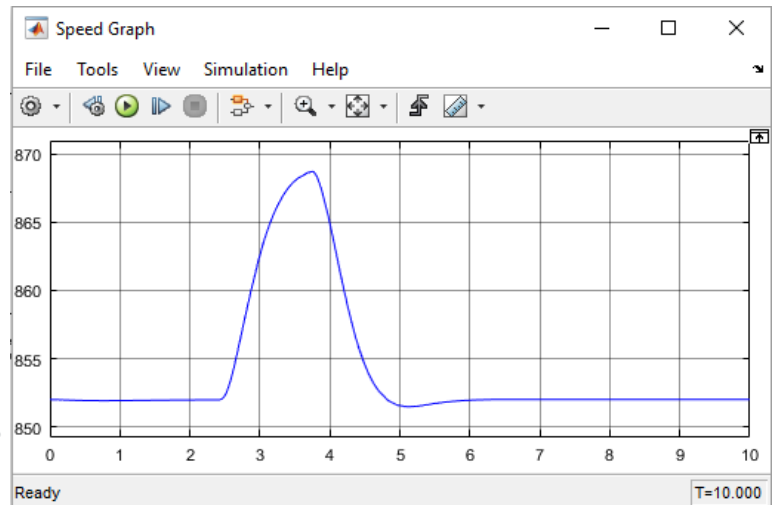

(b)

Figure 15. (a) Graphic of the System with Variation Load (b) Graphic of the System with Variation Load at Simulink Model

\section{Investigation Model}

The input data for the Simulink model engine is the desired value for viewing the performance of the engine. The input data used is to see the performance of the engine at $100 \%$ power and $100 \%$ speed and in the condition of variation speed and load.

Limit fuel will be variation with condition $100 \%$ of power and $110 \%$ of power.

a. Limit Fuel at $100 \%$ at Power

In this condition, the PI controller's fuel consumption limitation, located on the engine control block is set to $100 \%$ power. So, the maximum fuel consumption based on the equation 1 obtained value of $210.8 \mathrm{Kg} / \mathrm{h}$.

b. Limit Fuel at $110 \%$ of Power

In this condition, the PI controller's fuel consumption restriction located on the engine control block is set at
$110 \%$ power. So, the maximum fuel consumption based on the equation 1 obtained value of $231.85 \mathrm{Kg} / \mathrm{h}$.

\section{Investigation Model with Variation Load}

Where loads will be varied under one step load and more step load (unstable condition) to compare engine fuel consumption used and compare different fuel consumption limits.

\section{a. One Step Load}

The model can visualize the conditions in which the engine accepts load changes at a time. Simulink modeling uses $10000 \mathrm{Nm}$ load for 50 seconds and then converted to $8000 \mathrm{Nm}$ at 50 to 100 seconds. Resulting in graph in figure 16.

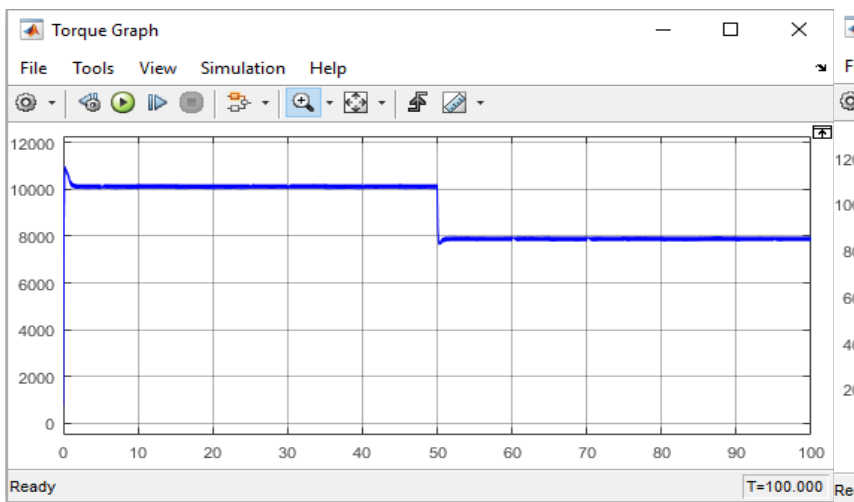

(a)

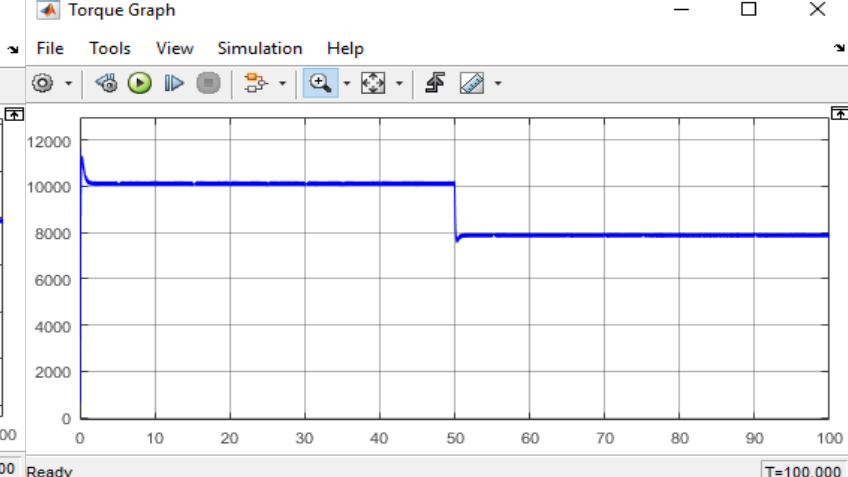

(b)

Figure. 16. (a) Graphic of the Load at One Step Condition (100\% of Power) (b) Graphic of the Load at One Step Condition (110\% of Power) 

(pISSN: 2541-5972, eISSN: 2548-1479)

\section{b. Unstable Load}

the model can visualize the conditions in which the engine accepts load changes every 5 seconds. Simulink modeling uses $10000 \mathrm{Nm}$ and $8000 \mathrm{Nm}$ up and down repeatedly during the process. Resulting in graph in figure 17.

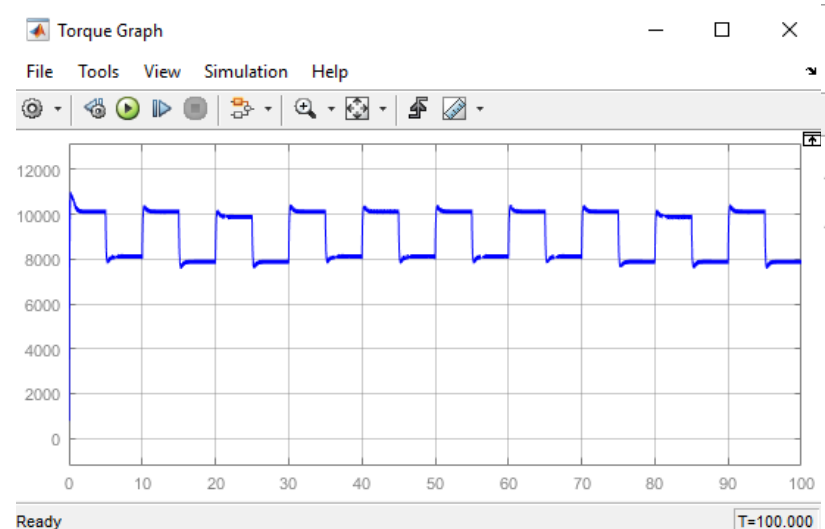

(a)

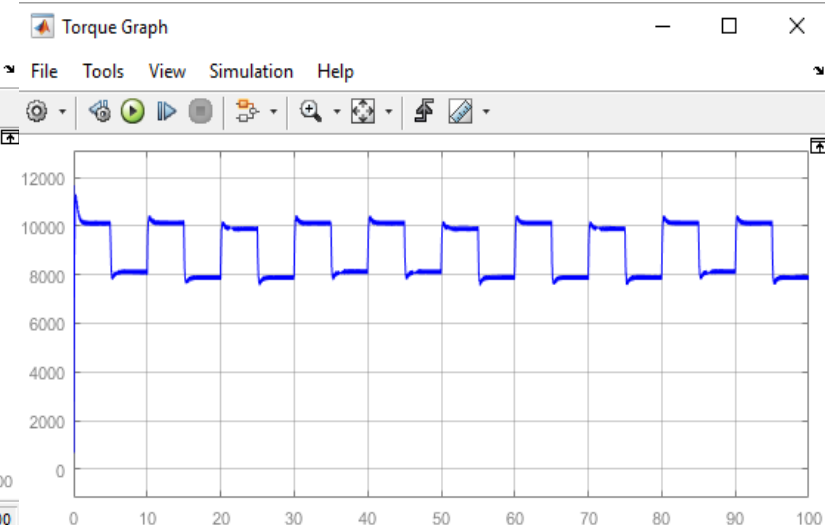

(b)

Figure. 17. (a) Graphic of the Load at Unstable Condition (100\% of Power) (b) Graphic of the Load at Unstable Condition (110\% of Power)

2. Investigation Model with Variation Speed

Where speed will be varied under one step speed and more step speed (unstable condition) to compare engine fuel consumption used and compare different fuel consumption limits and torque is constants. The result of graph speed can be seen on figure 18 .

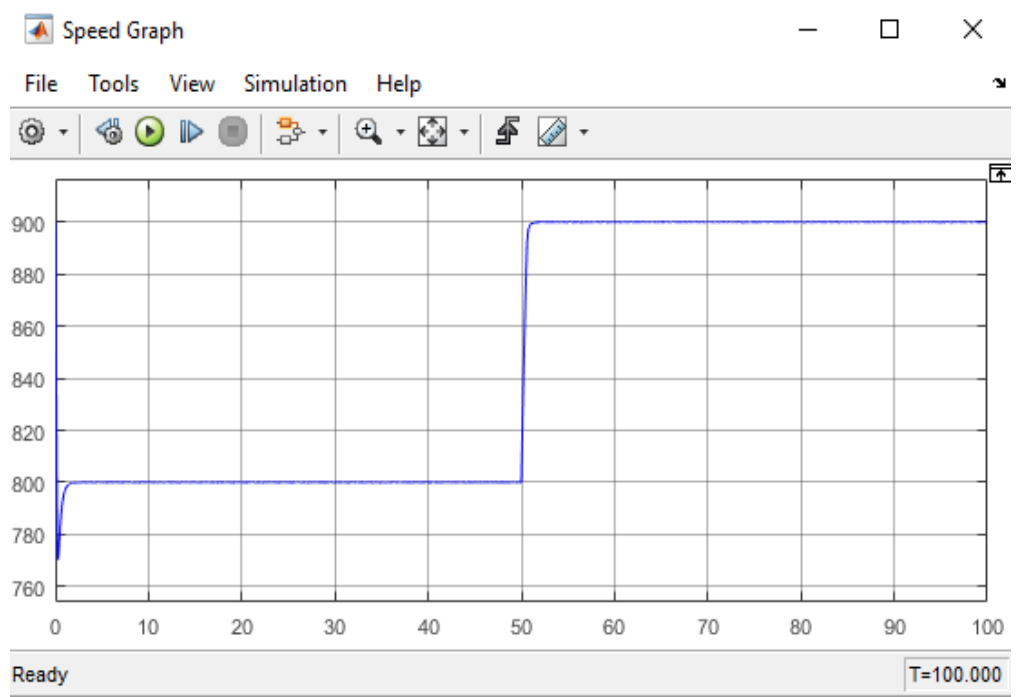

Figure. 18. Graph of the Speed at one step speed condition

a. One Step Speed

The model can visualize the conditions in which the engine accepts speed changes at a time. Simulink modeling uses $800 \mathrm{rpm}$ load for 50 seconds and then converted to $900 \mathrm{rpm}$ at 50 to 100 seconds. Resulting in graph speed in figure 19 .

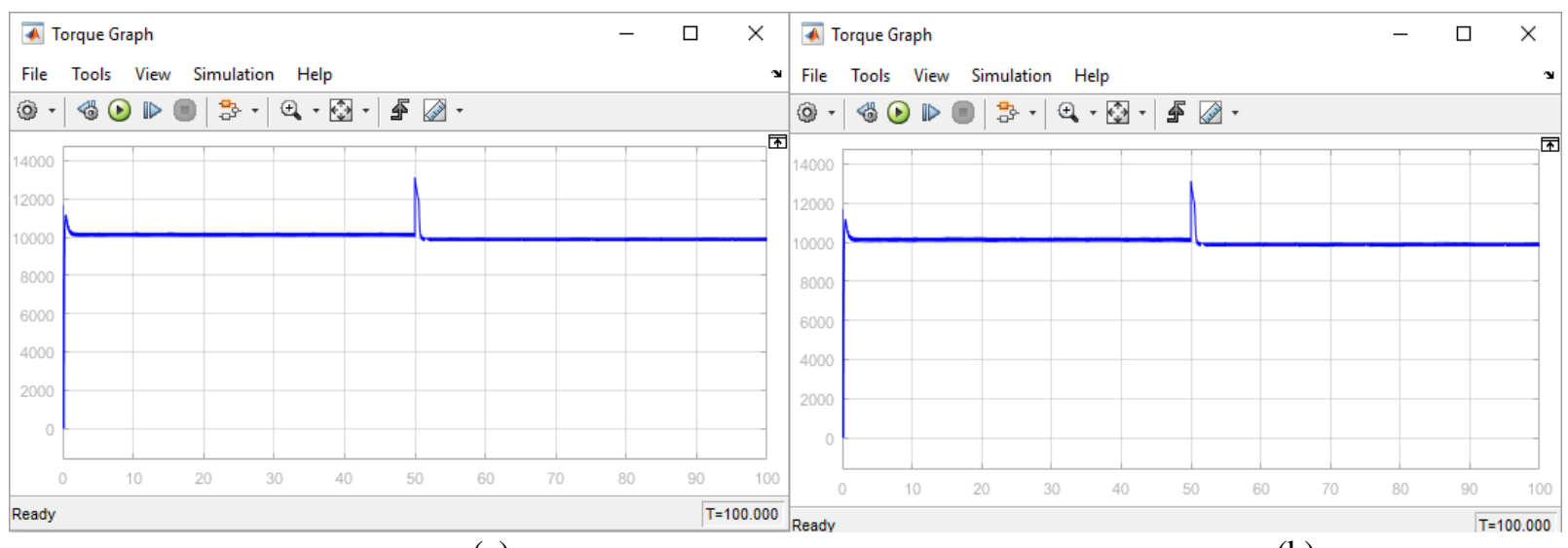

(a)

(b)

Figure. 19. (a) Graphic of the Torque at One Step Speed Condition (100\% of Power) (b) Graphic of the Torque at One Step Speed Condition (110\% of Power) 


\section{b. Unstable Speed}

The model can visualize the conditions in which the engine accepts speed changes every 5 seconds. Simulink modeling uses $900 \mathrm{rpm}$ and $800 \mathrm{rpm}$ up and down repeatedly during the process. The result of graph speed at unstable speed condition can be seen on figure 20. On the other hand, the result of torque at unstable speed condition at $100 \%$ and $110 \%$ power are shown on figure 21 (a) and figure 21 (b) respectively.
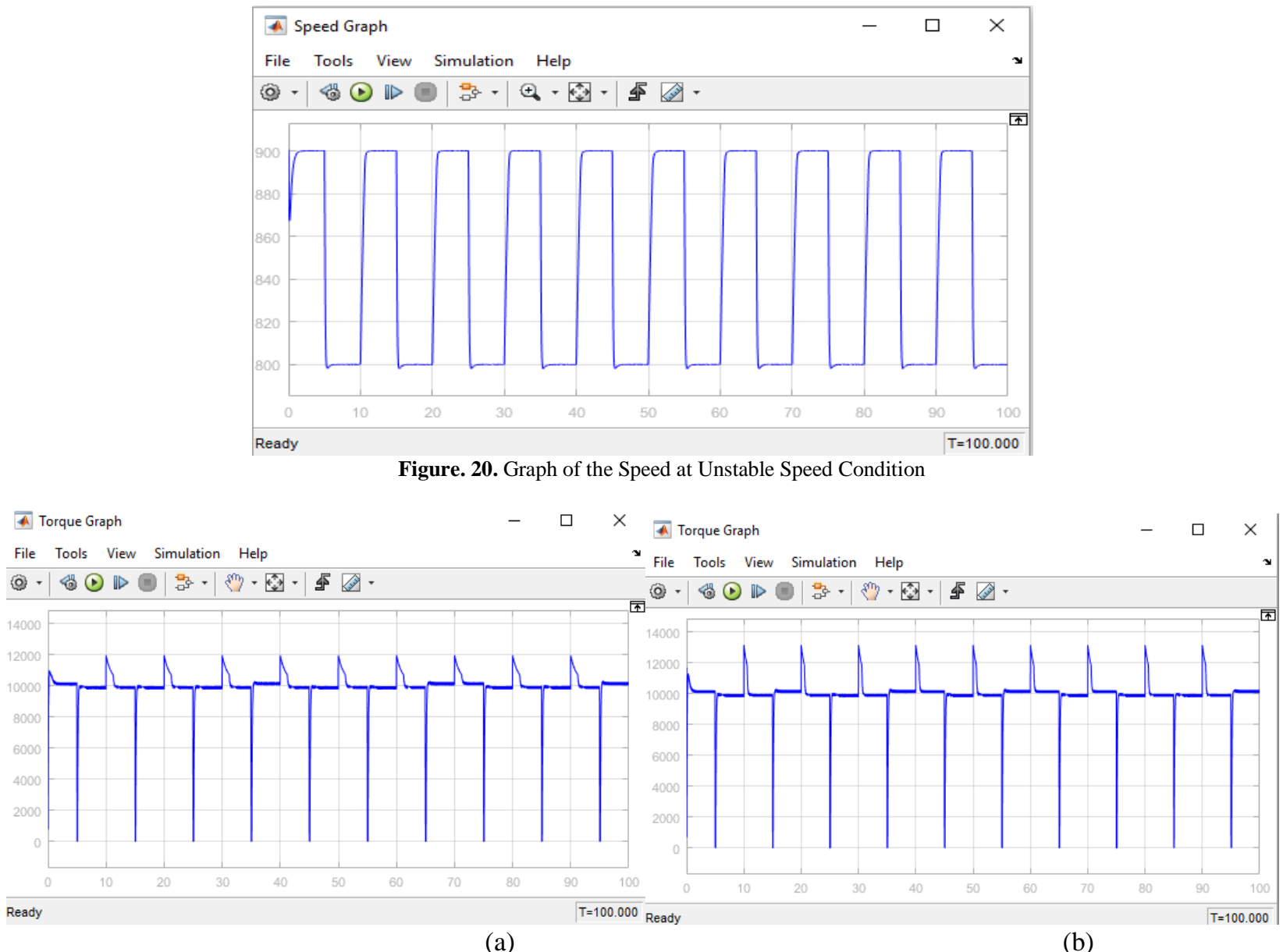

Figure. 21. (a) Graphic of the Torque at Unstable Speed Condition (100\% of Power) (b) Graphic of the Torque at Unstable Speed Condition (110\% of Power)

\section{Investigation for the Condition Engine}

In these conditions, the PI controller parameter parameters is varied to see the response on the system.

\section{a. Slow Condition}

In this condition, the PI controller parameter is set to give a slow response. This condition allows to be applied to the engine but this condition does not provide effective working engine. In this condition, the value of $\mathrm{P}$ and I parameters on PI controller of load and PI controller of the engine is set respectively 1 . The result of engine at slow condition can be seen on figure 22

\section{b. Stable Condition}

The stable condition is a good enough condition for engine performance. In this condition, the PI controller parameter is set to provide a quick response by providing stable conditions. In this condition, the engine works effectively. In this condition, the $\mathrm{P}$ and I parameter values on the PI controller of load are 1 and 100. The P and I parameters in the PI controller of engine are set to 4.5 and 13. The result of engine at stable condition can be seen on figure 23

\section{c. Dangerous Condition}

This condition is very dangerous when applied to the engine. In this condition, the PI controller parameter is set to provide a very fast response but gives a considerable oscillation value. So, it is dangerous for the engine condition. The limit of the given oscillation value is $10 \%$ of the given load value. In this condition, the engine works by being forced to get a very fast response time. In this condition, the $\mathrm{P}$ and I parameter values on the PI controller of load are 1 and 100. The P and I parameters in the PI controller of engine are set at 30 and 13. The result of engine at dangerous condition can be seen on figure 24 . 
(pISSN: 2541-5972, eISSN: 2548-1479)

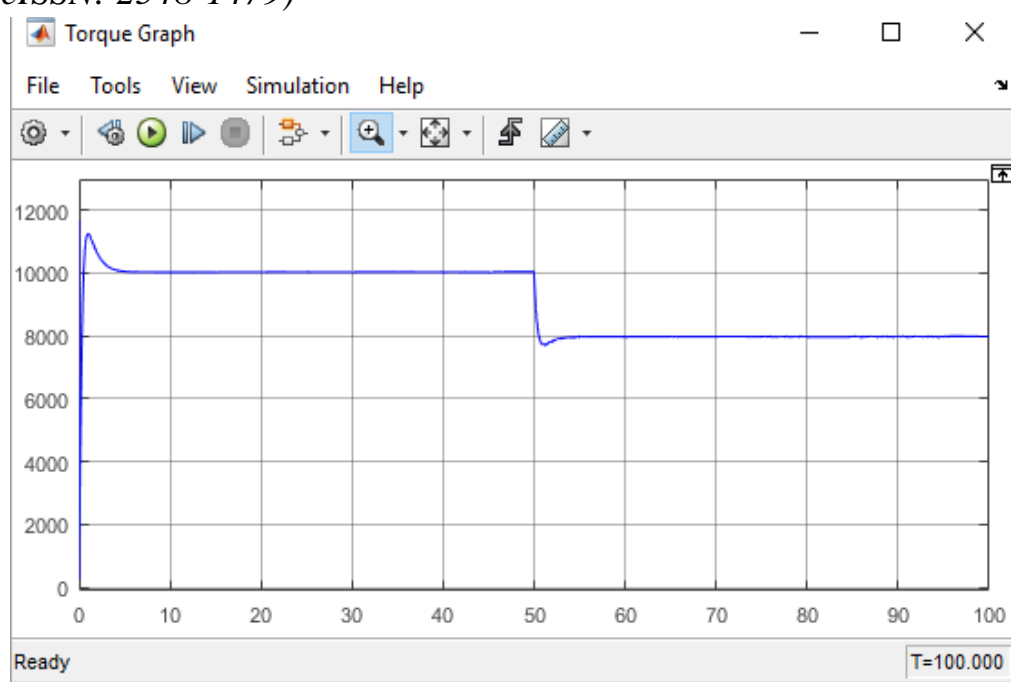

Figure. 22. Graph of the Slow Condition

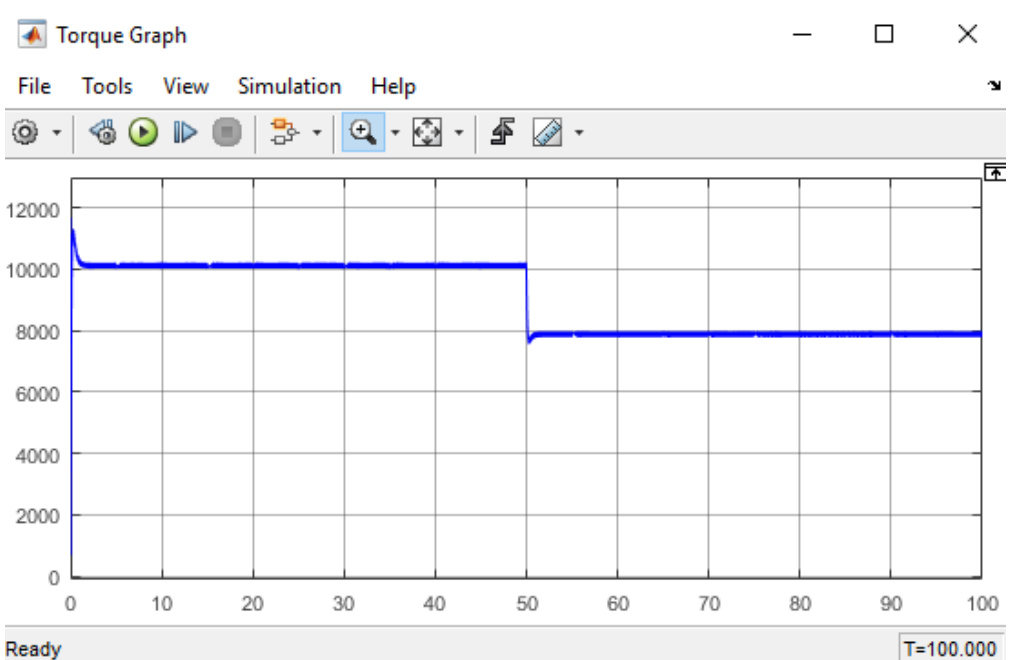

Figure. 23. Graph of the Stable Condition

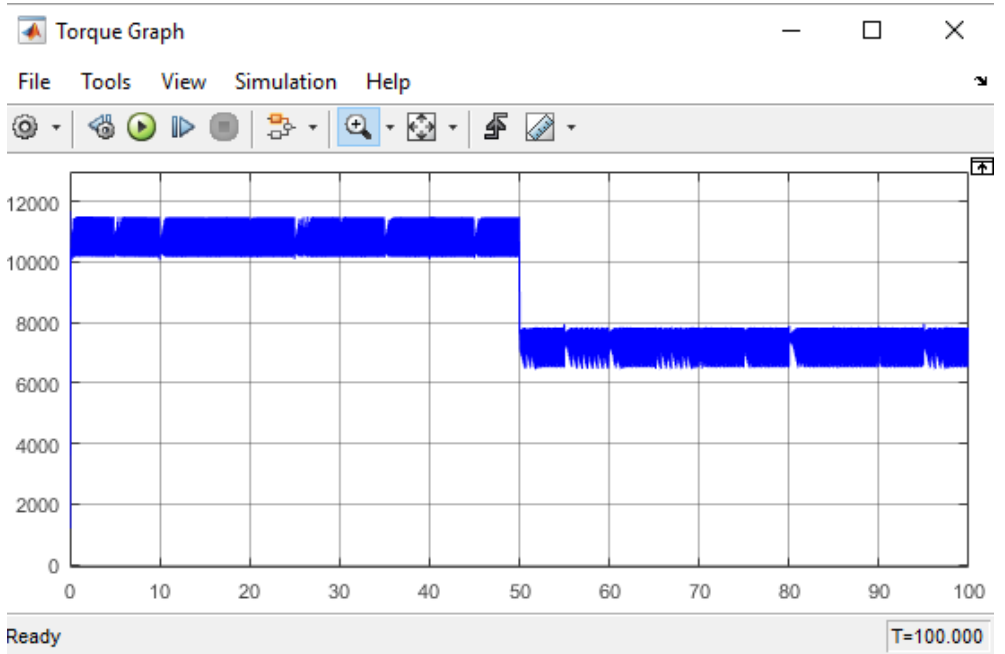

Figure. 24. Graph of the Dangerous Condition

\section{CONCLUSION}

\section{A. Conclusions}

Based on the result, the conclusion of this research are:

1. The lever for the performance of ENITECH offers the possibility to intervene in the process and to control the torque absorbed by the brake.
2. Engine stability can be seen from the power generated engine. Where the power engine depends on the amount of fuel that goes into the engine.

3. By using Proportional parameter value of 4.5 and Integral of 13 on PI controller, to get a more stable system so that used limitation of fuel rate is 231.85 $\mathrm{Kg} / \mathrm{h}$ or $110 \%$ power engine.

4. The static model serves to provide the relationship curve of the steady state model between input and output signals. 
(pISSN: 2541-5972, eISSN: 2548-1479)

5. The average power losses at engine is $4,375 \%$ and torque losses $2,525 \%$.

6. The factor value of ' $a$ ' 137.63 and ' $b$ ' is 496.86 with an average error of 0.005125 . Factor value for speed measurement is 351,87 .

7. Based on the model validation results on the static model and dynamic model and on the investigation with other cases, so that the corresponding PI controller parameter values obtained on the engine control are for proportional (P) 4.5 and for Integral (I) 13. With the limit fuel of $231.85 \mathrm{Kg} / \mathrm{h}$. The PI controller parameters on the load control are for proportional (P) 1 and for Integral (I) 100 values.

\section{REFERENCES}

[1] MAN B\&W: L23/30A Project Guide. Four-stroke Propulsion Engine compliant with IMO Tier II. Augsburg:2014
[2] Zöllner GmbH: Betriebsanleitung der Zöllner HydraulikLeistungsbremse Typ 9N38/12F, Fabrikatsnummer 3986, Arbeitsnummer 30 0783, 1989

[3] Hodgson, P. G.: Theoretical Model And Dynamic Simulation Of Variable Fill Hydraulic Dynamometers. Christchurch, 1991

[4] Simulink. (n.d.). Retrieved from MathWorks: https://www.mathworks.com/products /simulink. html

[5] Documentation of ENITECH Energietechnik-Elektronik $\mathrm{GmbH}$ for the main engine test stand $\mathrm{H} 5$ of the HS Wismar / Warnemünde, Department of Seafaring, Project: 705 (12005) dated 14.06.2013, editor R. Stahl.

[6] Adji, S.W. (2005). Engine Propeller Mathcing [File PDF]. Available in https://pt.slideshare.net

[7] Takahashi. (2007). PID Control [File PDF]. Available in http://act.rasip.fer.hr/

[8] Voith. Variable Speed Fluid Couplings-Technical Information, [png]. Ontained 21 March 2017, from http://www.voith.com/en/products-services/power-

transmission /variable -speed-drives/ variable -speed-fluidcouplings-57899. html. 